\section{STUDIES ON VALIDAMYGINS, NEW ANTIBIOTICS. VI}

\section{VALIDAMINE, HYDROXYVALIDAMINE AND \\ VALIDATOL, NEW CYCLITOLS}

Sir :

In this communication we wish to describe the structure elucidation of validamine, Ia, and hydroxyvalidamine, II ${ }^{1)}$, which were obtained from validamycin $A$ and validamycin $\mathrm{B}$, respectively, by hydrogenolysis, followed by acid hydrolysis. This communication also discusses the determination of the structures of validatol, IIIa, and deoxyvalidatol IV ${ }^{1)}$, which were obtained from both validamycins $\mathrm{A}$ and $\mathrm{B}$ by hydrogenolysis.

Validamine was crystallized as its monohydrochloride $\left(\mathrm{C}_{7} \mathrm{H}_{10} \mathrm{NO}_{4} \cdot \mathrm{HCl}^{*}\right.$; m.p. 229 $\left.232^{\circ} \mathrm{C}\right)$ (decomp.); $[\alpha]_{\mathrm{D}}+57.4^{\circ}(1 \mathrm{~N} \mathrm{HCl})$; $\mathrm{pKa}^{\prime}$ 8.2; positive to ninhydrin and LeMIEUx tests, negative to anthrone and FeHLing tests).

Validamine has one primary amino group ( $V_{\mathrm{AN}} \mathrm{S}_{\mathrm{LyKE}}$ ) and four hydroxyl groups. A periodate oxidation experiment (consumption of three moles of periodate) proves the four-carbon sequence which has one primary amino group and three secondary hydroxyl groups.

In the $\mathrm{nmr}$ spectrum $\left(\mathrm{D}_{2} \mathrm{O}\right)$ of validamine hydrochloride, integration revealed three protons (one tertiary and two ring-methylene protons) in the region $\delta 1.8 \sim 2.5$.

Validamine forms a pentaacetate, Ib, whose $\mathrm{nmr}$ ** spectrum $\left(\mathrm{CDCl}_{3}\right)$ shows eighteen protons in the region $\delta 1.5 \sim 2.5$, fifteen of them belcnging to the five acetate methyl groups. The axial ring-methylene $\mathrm{pro}^{+} \mathrm{cn}$ $(\delta 1.65, \mathrm{H}-6 \mathrm{a})$ shows splitting due to coupling with one geminal, one vicinal axial, and one vicinal equatorial protons. The equatorial ring-methylene proton $(\mathrm{H}-6 \mathrm{e})$ was presumably masked by the acetate methyl signals. The tertiary ring proton $(\delta 2.15$, $\mathrm{H}-5)$ is coupled with the side-chain methylene protons $\left(\mathrm{AcO}-\mathrm{CH}_{2}-, \mathrm{H}-7\right)$, the latter appeared as a pair of quartets centered at $\delta 3.90(\mathrm{~J}=11.4 \mathrm{~Hz}, \mathrm{~J}=3.3 \mathrm{~Hz})$ and $\delta 4.14$ $(\mathrm{J}=11.4 \mathrm{~Hz}, \mathrm{~J}=4.7 \mathrm{~Hz})$ which were decoupled into an $\mathrm{AB}$ quartet by irradiation of the $\mathrm{H}-5$ proton. This pattern establishes that a hydroxymethyl group is attached to a carbon having a single proton and no oxygen substituent.***

Deuterium exchange simplified the spec-

Table 1. NMR spectral data $\left(100 \mathrm{MHz}\right.$ in $\left.\mathrm{CDCl}_{3}\right)$

\begin{tabular}{|c|c|c|c|c|c|c|c|c|}
\hline \multicolumn{3}{|c|}{ Pentaacetylvalidamine (Ib) } & \multicolumn{3}{|c|}{ Hexaacetylhydroxyvalidamine (IIb) } & \multicolumn{3}{|c|}{ Tetraacetylvalidatol (IIIb) } \\
\hline & $\delta(\mathrm{ppm})$ & $\mathrm{J}(\mathrm{Hz})$ & & $\delta(\mathrm{ppm})$ & $\mathrm{J}(\mathrm{Hz})$ & & $\delta(\mathrm{ppm})$ & $\mathrm{J}(\mathrm{Hz})$ \\
\hline $\mathrm{H}-1$ & $4.56(1 \mathrm{H}, \mathrm{m})$ & $\mathrm{J}_{1,2}=4.5$ & $\mathrm{H}-1$ & $4.51(1 \mathrm{H}, \mathrm{m})$ & & $\mathrm{H}-1$ & $2.42(1 \mathrm{H}, \mathrm{m})$ & $\mathrm{J}_{1,2}=4.6$ \\
\hline $\mathrm{H}-2$ & $4.95(1 \mathrm{H}, \mathrm{q})$ & $\mathrm{J}_{2,3}=10$ & $\mathrm{H}-2$ & & & $\mathrm{H}-2$ & $4.96(1 \mathrm{H}, \mathrm{q})$ & $\mathrm{J}_{2,3}=8.0$ \\
\hline $\mathrm{H}-3$ & $5.28(1 \mathrm{H}, \mathrm{q})$ & $\mathrm{J}_{3,4}=9$ & $\mathrm{H}-3$ & $5.0 \sim 5.4$ & & $\mathrm{H}-3$ & $5.16(1 \mathrm{H}, \mathrm{q})$ & $\mathrm{J}_{3,4}=7.2$ \\
\hline $\mathrm{H}-4$ & $4.96(1 \mathrm{H}, \mathrm{q})$ & $\mathrm{J}_{4,5}=10.5$ & $\mathrm{H}-4$ & $(3 \mathrm{H}, \mathrm{m})$ & & $\mathrm{H}-4$ & $4.83(1 \mathrm{H}, \mathrm{m})$ & \\
\hline $\mathrm{H}-5$ & $2.15(1 \mathrm{H}, \mathrm{m})$ & & $\mathrm{H}-5$ & $2.45(1 \mathrm{H}, \mathrm{m})$ & & $\mathrm{H}-5$ & $1.5 \sim 2.3$ & \\
\hline$H-6 a *$ & $1.65(1 \mathrm{H}, \mathrm{m})$ & & $\mathrm{H}-6$ & $5.44(1 \mathrm{H}, \mathrm{t})$ & $\mathrm{J}=\sim 3$ & $\mathrm{H}-6$ & $(4 \mathrm{H}, \mathrm{m})$ & \\
\hline $\mathrm{H}-7$ & $3.90(1 \mathrm{H}, \mathrm{q})$ & $\mathrm{J}=11.4 \& 3.3$ & $\mathrm{H}-7$ & $3.93(1 \mathrm{H}, \mathrm{q})$ & $\mathrm{J}=11.4 \& 4.5$ & $\mathrm{H}-7$ & $4.15(2 \mathrm{H}, \mathrm{d})$ & $J=7$ \\
\hline & $4.14(1 \mathrm{H}, \mathrm{q})$ & $\mathrm{J}=11.4 \& 4.7$ & & $4.16(1 \mathrm{H}, \mathrm{q})$ & $\mathrm{J}=11.4 \& 8.0$ & & & \\
\hline $\begin{array}{l}\mathrm{NH} \text { on } \\
\mathrm{C}-1\end{array}$ & $6.26(1 \mathrm{H}, \mathrm{d})$ & $\mathrm{J}=7.3$ & $\begin{array}{l}\mathrm{NH} \text { on } \\
\mathrm{C}-1\end{array}$ & $6.33(1 \mathrm{H}, \mathrm{d})$ & $\mathrm{J}=7.3$ & & & \\
\hline $\begin{array}{l}\mathrm{C}-\mathrm{CH}_{3} \\
\mathrm{O}\end{array}$ & \multicolumn{2}{|c|}{$2.00(6 \mathrm{H}, \mathrm{s}), 2.02(3 \mathrm{H}, \mathrm{s})$} & $\left|\begin{array}{l}\mathrm{C}-\mathrm{CH}_{3} \\
\mathrm{O}\end{array}\right|$ & \multirow{2}{*}{\multicolumn{2}{|c|}{$2.00(12 \mathrm{H}, \mathrm{s}), 2.04(3 \mathrm{H}, \mathrm{s})$}} & $\begin{array}{l}\mathrm{C}-\mathrm{CH}_{3} \\
\mathrm{O}\end{array}$ & \multirow{2}{*}{\multicolumn{2}{|c|}{$\begin{array}{l}2.01(3 \mathrm{H}, \mathrm{s}) \\
\quad 2.02(3 \mathrm{H}, \mathrm{s}) \\
2.05(6 \mathrm{H}, \mathrm{s})\end{array}$}} \\
\hline & $2.03(3 \mathrm{H}, \mathrm{s})$ & $2.04(3 \mathrm{H}, \mathrm{s})$ & & & & & & \\
\hline
\end{tabular}

* The H-6e was presumably masked by the acetate methyl signals.

* Compounds characterized by melting points gave satisfactory elemental analyses.

** Unless otherwise noted, nmr spectra were taken at $100 \mathrm{MHz}$. For nmr studies of pseudo-sugars (cyclic monosaccharides whose ring-oxygen atoms have been replaced by methylene groups) see references 2,3 and 4 .

*** The signal of the tertiary ring proton of the pseudo-sugar acetate is shifted about 2 ppm upfield compared with a sugar acetate, due to the absence of the ring-oxygen ${ }^{3)}$. 
Fig. 1. NMR spectra of pentaacetylvalidamine (Ib).
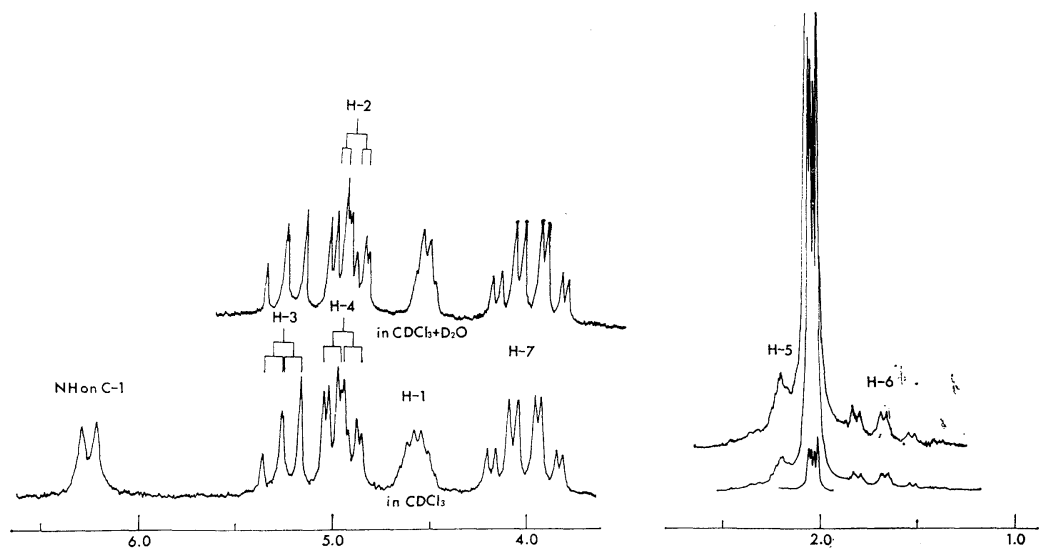

trum by eliminating the acetamido proton signal $(\delta 6.26, \mathrm{~J}=7.3 \mathrm{~Hz}, \mathrm{NH}$ on $\mathrm{C}-1)$ and revealed the expected simplifications in the multiplet at $\delta 4.56$, which was assigned as the $\mathrm{AcN}-\mathrm{CH}-$ ring proton.

The remaining three $\mathrm{AcO}-\mathrm{CH}$ ring protons produced two overlapping quartets $(\delta 4.95$, $\mathrm{H}-2$ and $\delta$ 4.96, $\mathrm{H}-4)$ and one quartet (triplet-like in appearance, $\delta-5.28, \mathrm{H}-3$ ).

The downfield position of the resonance of the $\mathrm{H}-3$ proton was presumably due to $1,3-$ diaxial deshielding by the acetamido group.

Irradiation of the $\mathrm{H}-5$ proton gives a doublet $(\mathrm{J}=9 \mathrm{~Hz})$ for the $\mathrm{H}-4$ proton; similarly, appropriate spectral changes of the $\mathrm{H}-1$ proton were noted by irradiating the H-6 proton.

The splitting patterns of the $\mathrm{H}-3$ and $\mathrm{H}-4$ protons $\left(\mathrm{J}_{2,3}=10 \mathrm{~Hz}, \mathrm{~J}_{3,4}=9\right.$ $\mathrm{Hz}$, and $\mathrm{J}_{4,5}=10.5 \mathrm{~Hz}$ ) can be explained by the coupling of vicinal axial protons, while the pattern for the $\mathrm{H}-4$ proton indicates that the $\mathrm{H}-4$ proton must be coupled

Chart 1.

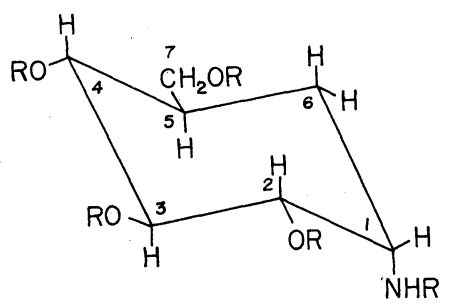

I a $\mathrm{R}=\mathrm{H}$; Validamine

I b $\quad \mathrm{R}=\mathrm{COCH}_{3}$ with the axial H-5 proton and not coupled with the methylene protons $(\mathrm{H}-6)$.

The splitting pattern of the $\mathrm{H}-2$ proton $\left(\mathrm{J}_{1,2}=4.5 \mathrm{~Hz}, \mathrm{~J}_{2,3}=10 \mathrm{~Hz}\right)$ is typical of an axial proton having one axial and one equatorial neighboring proton, clearly suggesting the equatorial conformation of the $\mathrm{H}-1$ proton.

The above data established the structure of validamine as $(1 S)-(1,2,4 / 3,5)-1$-amino-5hydroxymethyl-2,3,4-cyclohexanetriol or its mirror image.

The absolute configuration of validamine has been established as $(1 S)-(1,2,4 / 3,5)$ by $\mathrm{X}$-ray crystallography of validamine monohydrobromide and will be reported in detail in a subsequent communication by $\mathrm{K}$. KAMIYA, et al.

Fig. 2. NMR spectrum of hexaacetylhydroxyvalidamine (IIb).

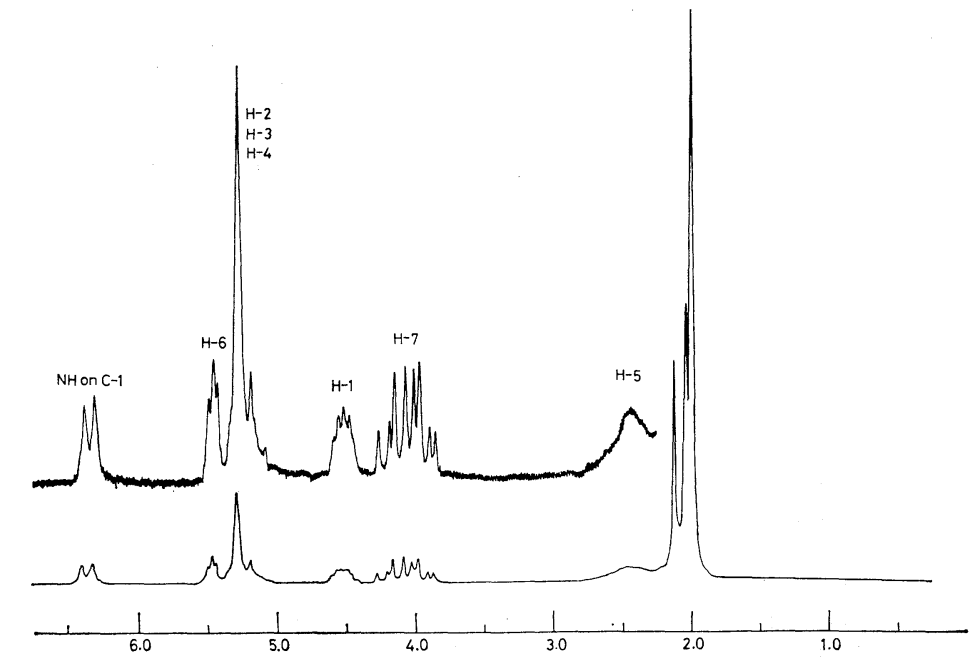


The same conclusion has been reached by comparison of the optical rotation of validamine with that of $\alpha-\mathrm{D}$-glucose and $\alpha-\mathrm{L}-$ glucose, because the structure of validamine is identical with that of an $\alpha-\mathrm{D}$-glucose whose ring-oxygen atom has been replaced by a methylene and whose anomeric hydroxyl group has been replaced by a primary amino group. The $S$ configuration at $\mathrm{C}-1$ was further confirmed by LEMIEUx's empirical rules for estimating the optical rotation of cyclitols. ${ }^{5)}$

\section{Chart 2.}

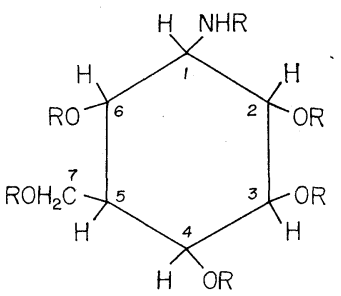

II a $\mathrm{R}=\mathrm{H}$; Hydroxyvalidamine

II b $\mathrm{R}=\mathrm{COCH}_{3}$

Crystalline hydroxyvalidamine (m.p. 164 $\left.165^{\circ} \mathrm{C} ;[\alpha]_{\mathrm{D}}+80.7^{\circ}\left(\mathrm{H}_{2} \mathrm{O}\right) ; \mathrm{pKa}^{\prime} 7.0\right)$ has the molecular formula $\mathrm{C}_{7} \mathrm{H}_{15} \mathrm{NO}_{5}$, differing from validamine's molecular formula by one oxygen atom.

Hydroxyvalidamine has one primary amino group (VAN SlyKe) and five hydroxyl groups, and consumes four moles of periodate.

The $\mathrm{nmr}$ spectrum $\left(\mathrm{D}_{2} \mathrm{O}\right)$ of hydroxyvalidamine has a multiplet at $\delta 2.15$ (tertiary ring proton, $\mathrm{H}-5)$, a triplet at $\delta 3.46(\mathrm{~N}-$ $\mathrm{CH}$ ring proton, $\mathrm{J}=c a .3 \mathrm{~Hz}, \mathrm{H}-1)$ a triplet at $\delta 4.27(\mathrm{O}-\mathrm{CH}$ ring proton, $\mathrm{J}=c a .3 \sim 4$ $\mathrm{Hz}, \mathrm{H}-6)$ and no signal for a ring-methylene proton.

The sequnce of three carbons $(\mathrm{C}-1, \mathrm{C}-6$, $\mathrm{C}-5)$ was confirmed by spin decoupling.

Hydroxyvalidamine forms the hexaacetate IIb, whose nmr spectrum shows two sidechain methylene protons $(\delta 3.93$, quartet, $\mathrm{J}=11.4 \mathrm{~Hz}, \mathrm{~J}=4.5 \mathrm{~Hz}$ and $\delta 4.16$, quartet, $\mathrm{J}=$ $\left.11.4 \mathrm{~Hz}, \mathrm{~J}=8.0 \mathrm{~Hz}, \mathrm{AcO}-\mathrm{CH}_{2}-\mathrm{H}-7\right)$ which are coupled with the tertiary ring proton ( $\delta$ 2.45, multiplet, $\mathrm{H}-5$ ). There must then be an $\mathrm{AcO}-\mathrm{CH}_{2}-{ }^{\prime} \mathrm{H}$ system in hexaacetylhydroxyvalidamine.

The doublet at $\delta 6.33(\mathrm{~J}=7.3 \mathrm{~Hz}, \mathrm{AcNH}-$, $\mathrm{NH}$ on $\mathrm{C}-1$ ) was lost on exchange with $\mathrm{D}_{2} \mathrm{O}$, which also revealed the expected simplification in the $\mathrm{H}-1$ pattern at $\delta 4.51$, assigned to the $\mathrm{AcN}-\mathrm{CH}$ ring proton $(\mathrm{H}-1)$. The triplet at $\delta 5.44(\mathrm{O}-\mathrm{CH}$ ring proton, $\mathrm{H}-6)$ is coupled with the $\mathrm{H}-1$ and $\mathrm{H}-5$ protons.

Combination of the four-carbon sequence (in the order $\mathrm{C}-1, \mathrm{C}-6, \mathrm{C}-5$ and $\mathrm{C}-7$ ) and the remaining three-carbon sequence $(\mathrm{C}-2$, $\mathrm{C}-3$, and $\mathrm{C}-4$ ) which has three $\mathrm{AcO}-\mathrm{CH}$ ring protons in the region $\delta 5.0 \sim 5.4$ gave the structure of hydroxyvalidamine as 1amino-5-hydrcxymethyl-2, 3, 4, 6-cyclohexanetetrol.

The acetate methyl pattern of hexaacetylhydroxyvalidamine consisted of three signals

Fig. 3. NMR and double resonance spectra of tetraacetylvalidatol (IIIb).

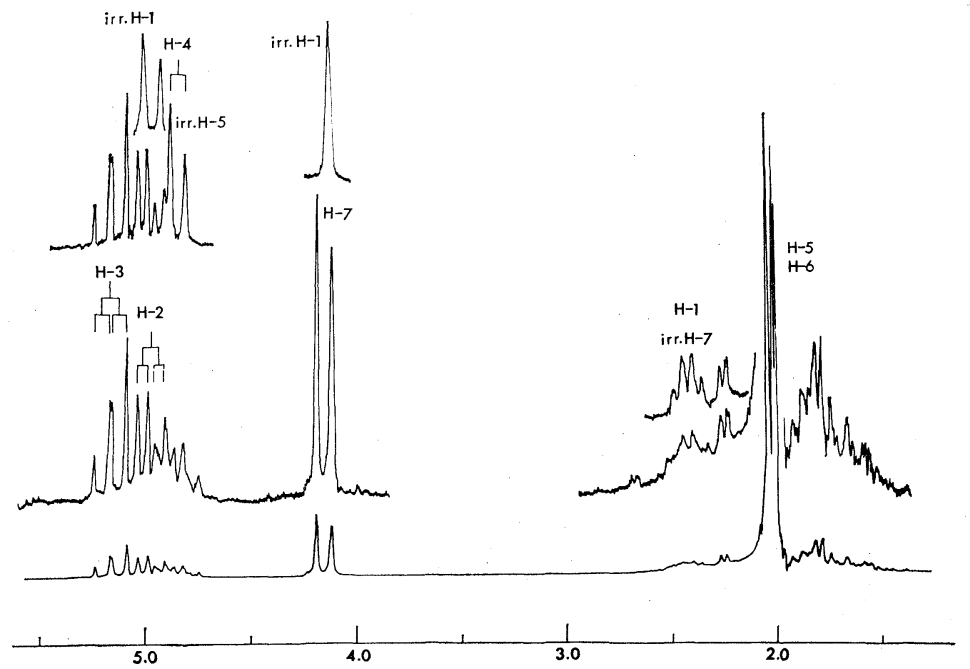


Chart 3.

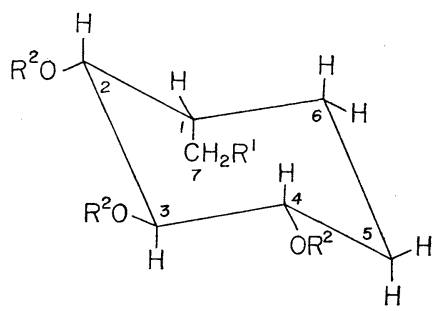

III a $\mathrm{R}^{1}=\mathrm{OH}, \mathrm{R}^{2}=\mathrm{H}$; Validatol

III b $\mathrm{R}^{1}=\mathrm{OCOCH}_{3}, \mathrm{R}^{2}=\mathrm{COCH}_{3}$

IV $\mathrm{R}^{1}=\mathrm{R}^{2}=\mathrm{H}$; Deoxyvalidatol

at $\delta 2.12,2.04$, and 2.00 (three, three and twelve protons, respectively). The band width of its splitting pattern (triplet, $\mathrm{J}=c a$. $3 \mathrm{~Hz}$ ) and chemical schift for $\mathrm{H}-6$ suggest that one $(\mathrm{H}-6)$ of the four $(\mathrm{AcO}-\mathrm{CH})$ ring protons is an equatorial proton.

Analysis of the remaining three $\mathrm{O}-\mathrm{CH}$ ring protons was difficult even at $220 \mathrm{MHz}$ and the complete stereochemistry remains to be established.*

Validamine and hydroxyvalidamine represent the first recorded isolation from a natural source of aminocyclitols possessing a hydroxymethyl group.

Validatol $\left(\mathrm{C}_{7} \mathrm{H}_{14} \mathrm{O}_{4} ;\right.$ m.p. $119 \sim 121^{\circ} \mathrm{C} ;[\alpha]_{\mathrm{D}}$ $-39.0^{\circ}\left(\mathrm{H}_{2} \mathrm{O}\right)$ ) consumes two moles of pericdate and forms a tetraacetate, IIIb (mass spectrum $\mathrm{M}=\mathrm{m} / \mathrm{e} 330$ ).

The nmr spectrum $\left(D_{2} \mathrm{O}\right)$ of validatol shows the presence of four ring-methylene protons $(\delta 1.6 \sim 2.2)$, one tertiary ring proton $(\delta 2.41)$, and overlapping signals $(\delta 3.5 \sim 4.2)$ which consist of two side-chain methylene protons $\left(-\mathrm{CH}_{2} \mathrm{O}\right)$ and three $\mathrm{O}-\mathrm{CH}$ ring protons.

The nmr spectrum $\left(\mathrm{CDCl}_{3}\right)$ of validatol tetraacetate, IIIb, shows the doublet $(\delta 4.15$, $\mathrm{J}=7 \mathrm{~Hz}$ ) of the side-chain methylene protons (AcO- $\mathrm{CH}_{2}-, \mathrm{H}-7$ ), which are coupled with a tertiary ring proton $(\delta 2.42, \mathrm{H}-1)$. The $\mathrm{H}-1$ proton gave a complex, poorly resolved multiplet, which is decoupled to a quartet due to nearly equal coupling $(\mathrm{J}=4 \sim 5 \mathrm{~Hz})$ with three vicinal protons, by irradiation of the $\mathrm{H}-7$ protons; this suggests an equatorial conformation of the $\mathrm{H}-1$ proton.

The four ring-methylene protons produce an overlapping multiplet ( $\mathrm{H}-5, \mathrm{H}-6)$ which is partially masked by the twelve acetate methyl protons.

The remaining three $\mathrm{AcO}-\mathrm{CH}$ ring protons produced two quartets (centered at $\delta 4.96$, $\mathrm{H}-2$ and $\delta$ 5.16, $\mathrm{H}-3$ ) and one multiplet (centered at $\delta 4.83, \mathrm{H}-4)$ which is decoupled to a doublet $(\mathrm{J}=7.2 \mathrm{~Hz})$ by irradiation of the ring-methylene protons.

The downfield chemical shift of the $\mathrm{H}-3$ proton is presumably due to 1,3-diaxial deshielding by an acetoxymethyl group, and the large values of $\mathrm{J}_{2,3}=8.0 \mathrm{~Hz}$ and $\mathrm{J}_{3,4}=$ $7.2 \mathrm{~Hz}$ are characteristic of vicinal protons having axial conformations.

The $\mathrm{H}-2$ proton is coupled to the $\mathrm{H}-1$ proton by $\mathrm{J}=4.6 \mathrm{~Hz}$, clearly suggesting the axial conformation of the acetoxymethyl group.

The above data established the structure of validatol as $(1 S)-(1,2,4 / 3)-1$-hydroxymethyl-2,3,4-cyclohexanetriol or its mirror image.**

Deoxyvalidatol IV $\left(\mathrm{C}_{7} \mathrm{H}_{14} \mathrm{O}_{3} ;[\alpha]_{\mathrm{D}}-19.4^{\circ}\right.$ $\left(\mathrm{H}_{2} \mathrm{O}\right)$ ) consumes two moles of periodate. The nmr spectrum $\left(\mathrm{D}_{2} \mathrm{O}\right)$ of deoxyvalidatol shows the presence of one $\mathrm{C}$-methyl group $(\delta 1.16$, doublet, $\mathrm{J}=7 \mathrm{~Hz}$ ), four ring-methylene protons $(\delta 1.3 \sim 2.1)$, one tertiary ring proton $(\delta 2.35$, multiplet) and three $\mathrm{O}-\mathrm{CH}$ ring protons $(\delta 3.0 \sim 4.0)$. From the absence of a methyl group in the $\mathrm{nmr}$ spectra of validamycins $A$ and $B$, it is concluded that the methyl group of deoxyvalidatol arises from the hydroxymethyl group by further hydrogenolysis.

\section{Acknowledgement}

The authors are grateful to Dr. R. TAkeda and Dr. A. Mryake for their interest throughout this work. Thanks are also due to Mr. K. Kawahara for his technical assistance.

\section{SATOShi HorII \\ Takashi Iwasa \\ Eizi Mizuta \\ Yukiniko Kameda}

Microbiological Research Laboratories, Research and Development Division, Takeda Chemical Industries, Ltd. Higashiyodogawa-ku, Osaka, Japan

(Received September 24, 1970)

\footnotetext{
* The absolute structure, $(1 S)-(1,2,4 / 3,5,6)-1$-amino-5-hydroxymethyl-2,3,4,6-cyclohexanetetrol is most likely, by biogenetic analogy to validamine combined with the structural data above.

** Lemieux's empirical rules for estimating the optical rotation of cyclitols ${ }^{6}$ ) may serve to establish the absolute $S$ configuration at $\mathrm{C}-1$.
} 


\section{References}

1) Horit, S.; T. Iwasa \& Y. Kameda: Studies on validamycins, new antibiotics. V. Degradation studies. J. Antibiotics $24: 57 \sim 58$, 1971

2) McCasland, G. E. \& S. Furuta: Alicyclic carbohydrates. XXIX. The synthesis of a pseude-hexose $(2,3,4,5$-tetrahydroxycyclohexanemethanol). J. Org. Chem. $31: 1516 \sim$ 1521, 1966

3) McCasland, G.E.; S. Furuta \& L.J. Durham: Alicyclic carbohydrates. XXXII. Synthesis of pseudo- $\beta$-DL-gulopyranose from a diacetoxybutadiene. Proton magnetic resonance studies. J. Org. Chem. 33 : 2835 2841, 1968

4) McCasland, G.E.; S. Furuta \& L.J. Durham: Alicyclic carbohydrates. XXXIII. Epimerization of pseudo- $\alpha-\mathrm{DL}$-talopyranose to pseudo- $\alpha$-DL-galactopyranose. Proton magnetic resonance studies. J. Org. Chem. 33 : 2841 2844, 1968

5) Lemieux, R. U. \& J. C. Martin: Applications of empirical rules for optical rotation to problems of conformational analysis. Carbohyd. Res. 13 : 139 161, 1970 